\title{
The Effect of Chewing Gum on Periodontal Disease
}

\author{
Dr Alaa Omran Ali
}

BDS, MSc, Periodontal Department, College of Dentistry University of Baghdad

\begin{abstract}
Background: Chronic periodontitis is an inflammatory disease that affects the supporting tissues of the teeth and it's a common chronic adult condition. Chewing sugar-free gum helps protect your teeth and gums in between meals and it helps the mouth to produce more saliva. Aim of the study: To study the effect of chewing gum on a patient which have periodontal disease. Material and Method :A study of forty patient divuided into two group, chewing gum and non-chewing gum. The chewing gum group was composed of twenty patients and control gum group was composed also of twenty patients. The patient was selected from periodontal department in college of dentistry/university of Baghdad. The subjects for the study were selected randomly and they were in a good general health and were not using any medications and the subject we take contain male and female patients we carried out a careful examination of patients using the plaque index (PI)(silness and loe in 1964), Gingival index (GI) (silness and loe in 1964) of those patients make a comparison analysis. Result:The study demonstrate no significant differences between thee chewing and control group in the amount of plaque accumulation and also in the degree of gingival inflammation. Conclusion:as health care providers, we should include in our dental education programmes the role of chewing gum as an adjunct to individual self-care such as routine daily brushing, flossing and regular dental check. With the various community-based preventive measures underway, it is likely that chewing sugar-free gum can play an important role in the improvement of oral health status of the country.
\end{abstract}

Keywords: chewing gum periodontitis gingival index

\section{Introduction}

\section{Periodontits}

Periodontitis is defined as an inflammatory disease of the supporting tissues of the teeth caused by specific microorganisms or groups of specific microorganisms, resulting in progressive destruction of the periodontal ligament and alveolar bone with pocket formation, recession, or both. The clinical feature that distinguishes periodontitis from gingivitis is the presence of clinically detectable attachment loss ${ }^{(\mathbf{1})}$. This often is accompanied by periodontal pocket formation and changes in the density and height of subjacent alveolar bone. In some cases, recession of the marginal gingiva may accompany attachment loss. ${ }^{(2)}$

\section{History of Chewing Gum:}

It was reported that in $50 \mathrm{AD}$, the Greekssweetened their breath and cleansed theirteeth by using mastiche, a resin from thebark of mastic tree (masticate is derived fromthe root word mastiche). The ancient MayanIndians of Yucatan chewed tree resin (chicle)from the sapodilla tree. Spruce gum becamethe first chewing gum to be manufactured commercially as "State of Maine Pure Spruce Gum" in 1848. However its use was eventuallyreplaced by paraffin, which is still beingchewed in some areas ${ }^{(3)}$.

The first patent for chewing gum wasfiled by William $\mathrm{F}$ Sample (1869), a dentistfrom Mount Vernon, Ohio. This was initially intended to be used as a dentifrice. William Wrigley Jr. launched his first chewing gum(Lotta and Vassar) in the 1890s, followed byJuicy Fruit and Wrigley's Spearmint gum ${ }^{(4)}$.

Sugarless gums was introduced inearly 1950s with Sorbitol used as sugar substitute. The first brand to be marketed was Harvey's followed by Trident and Carefree in 1975. W. Wrigley Jr. introduced Freedent designedespecially for denture wearers, whichdo not stick to the dentures. Recaldent (Casein Phospho Peptide Amorphous Calcium Phosphate (CPP-ACP), a milk produce that can strengthens teeth and help prevent dentalcaries was introduced in $1999^{(5)}$

The global market for chewing gum isestimated to be 560,000 tonnes per year. Approximately 374 billion pieces of chewinggum are sold globally every year; representing 187 billion hours of gum chewing if eachpiece of gum is chewed for 30 minutes. Chewinggum can thus be expected to have an influenceof oral health ${ }^{(6)}$.

\section{Chewing Gum and Periodontal Health}

Presently some of the short-term advantages have been achieved with chewing gum include ${ }^{(7)}$ :

1) Stimulate saliva flow: By stimulating saliva production, chewing sugarfree gum can be an important defense mechanism to help protect teeth.

2) Reduce plaque: Chewing sugarfree gum has been associated with a reduction in the quantity and development of plaque on teeth, and a reduction in the acid-forming ability of plaque.

3) Neutralize acids: Salivary stimulation by chewing sugarfree gum after snacks or meals containing fermentable carbohydrate has been demonstrated to reduce the acidogenic potential of foods significantly.

4) Remineralize enamel: Stimulated saliva helps to restore minerals in tooth enamel, as levels of calcium and phosphate ions in the saliva increase due to stimulation caused by chewing gum.

5) Clean the mouth of food debris: Chewing sugarfree gum increases the rate of food debris clearance from teeth compared with not chewing gum during the initial 15 minutes after eating.

6) Relieve dry mouth discomfort: Stimulation of salivary flow caused by chewing gum can relieve some of the discomfort of xerostomia. In fact, chewing sugarfree gum has been shown to be one of the most preferred treatments for xerostomia.

Various studies have examinedthe effect on plaque, oral debris, calculusand gingivitis scores in subjects who chewed 


\section{International Journal of Science and Research (IJSR) \\ ISSN (Online): 2319-7064 \\ Index Copernicus Value (2015): 78.96 | Impact Factor (2015): 6.391}

gum, and compared with non chewing gum. The results are varying. Howeverchewing gum, irrespective of sweetener caused significantly less plaque accumulationthan not chewing gum. ${ }^{(8)}$

Five percent sodium bicarbonate (baking soda) incorporated in chewing gumwas found to have properties of reducing plaque, gingivitis and extrinsic stains when chewed two to three times a day. ${ }^{(9)}$ Incorporation of medicaments in chewing gum had further enhanced periodontal health care. Studies on chlorhexidine showed that chewingtwo pieces of chlorhexidinediacetate gum for 10 minutes twice a day (20mg/day) were aseffective as $40 \mathrm{mg} /$ day from rinses. The bittertaste and staining associated with rinses wereovercome by administering chlorhexidine inchewing gum formulation. ${ }^{(10)}$

A chlorhexidine/Xylitol combination inchewing gum showed reduction in plaque andgingivitis and supported oral hygiene routinesfor an elderly population when two pelletswere chewed twice for 15 minutes. ${ }^{(11)}$

Xylitol is a carbohydrate that is found in plants such as raspberries, corn, oats, mushrooms and birch trees. A natural sweetener, it is comparable to sucrose in sweetness but contains fewer calories. Xylitol was first used in large quantities in Finland in the 19th century, where it was extracted from birch trees. Very quickly, it became a popular sugar substitute in Europe and is now used as the primary sweetener in chewing gums all across Europe and east Asia. ${ }^{(12)}$

Xylitol is a carbohydrate that cannot be processed by harmful bacteria in the mouth that cause plaque, tooth decay, gum disease, and ear and sinus infections. These bacteria are not able to digest xylitol. Held in the mouth, xylitol also stimulates saliva flow. Additionally, xylitol has $40 \%$ fewer calories than sucrose and absorbs more slowly into the blood stream, reducing incidence of hyperglycemia. ${ }^{(13)}$

Clinical studies suggest that the benefits of xylitol are greatest when there is a continuous concentration of xylitol in your mouth. You must chew 2 to 3 pieces of gum 3 times a day (that's 6-9 pieces of gum a day!) to obtain the full benefits. Because XyliMelts is an adhering disc that releases effective concentrations of xylitol over time and you can use it while sleeping when saliva flow is lowest, you don't need to consume as much xylitol to achieve the same effect. This also means hours of relief for a dry mouth as the disc coats and moisturizes, releasing soothing oral lubricants and increasing saliva flow.* XyliMelts for Dry Mouth is designed for use while sleeping, when dry mouth is at its worst. ${ }^{(14)}$

Later,studies proved that Pycnogenol 5\% an antioxidantin corporated in chewing gum significantlyminimized gingival bleeding and plaque accumulation. ${ }^{(18)}$ Recently eucalyptus incorporatedin chewing gum $(0.6 \%$ i.e. $90 \mathrm{mg} /$ day $)$ was suggested to be useful in inhibiting dentalplaque formation (15) and promote periodontalhealth. Periodontal disease pathology It is not yet entirely clear. Many Studies have shown that the salivary $\mathrm{pH}$ altered in disease with increasing periodontal progression and disease severity. ${ }^{(16)}$
It was also postulated that after a successful treatment improve plaque control, resolve bleeding on probing and depth bag, salivary $\mathrm{pH}$ should decrease. ${ }^{(17)}$

When assessing the relationship between $\mathrm{pH}$ salivary and severity of the disease periodontal find a directly proportional relationship. It is so as disease observed progressed further alkalization of the $\mathrm{pH}$ of the saliva of the patients. (18)

This increase can be due to the urea concentration, which is diffused from saliva to the dental plaque. The urea is metabolized quickly by bacterial urease enzymes, producing ammonia and carbonic gas and causing an elevation in the $\mathrm{pH}$ of the saliva. ${ }^{(19)}$

However, in a recent study by Shu et al. , a larger urea level was verified in the dental plaque of caries-free individuals, suggesting that enzymatic activity can increase the $\mathrm{pH}$ and decrease the development of caries. ${ }^{(20)}$

\section{Material and Method}

A study of forty patient divided into two group, chewing gum and non-chewing gum. The chewing gum group was composed of twenty patients and control group was composed also of twenty patients. The patient was selected from periodontal department in college of dentistry/ university of Baghdad. The subjects for the study were selected randomly and they were in a good general health and were not using any medications and the subject we take contain male and female patients we carried out a careful examination of patients using the plaque index (PI)(silness and loe in 1964), Gingival index (GI) (silness and loe in 1964) of those patients make a comparison analysis.

\section{Method}

After doing scaling for the subjects We ask them to use a sugar free chewing gum one time daily for 20 minutes during the first week and we examined the subjects after the first and second week and we make a comparison analysis. A thorough periodontal examination was carried out under good artificial light, and parameter selected for the study were carefully record. plaque index, gingival index all were measured using these specific indices and recorded on a case-sheet design for this study. Informed consent was obtained from all the subjects before starting periodontal examination .

\section{Clinical examination \\ Plaque index:}

The plaque Index (Löe and Silness, 1963) was created for the assessment of the plaque accumalation on the basis of 0 to 3 . The criteria are: ${ }^{(61)}$

\begin{tabular}{|c|l|}
\hline Scores & \multicolumn{1}{|c|}{ Criteria } \\
\hline 0 & No plaque \\
\hline 1 & $\begin{array}{l}\text { A film of plaque adhering to the free gingival margin and } \\
\text { adjacent area of the tooth. The plaque may be seen in situ } \\
\text { only after application of disclosing solution or by using the } \\
\text { probe on the tooth surface. }\end{array}$ \\
\hline 2 & $\begin{array}{l}\text { Moderate accumulation of soft deposit s within the gingival } \\
\text { pocket, or the tooth and gingival margin which can be seen } \\
\text { with the naked eye. }\end{array}$ \\
\hline 3 & $\begin{array}{l}\text { Abundance of soft matter within the gingival pocket and/or } \\
\text { on the tooth and gingival margin. }\end{array}$ \\
\hline
\end{tabular}




\section{International Journal of Science and Research (IJSR) \\ ISSN (Online): 2319-7064}

Index Copernicus Value (2015): 78.96 | Impact Factor (2015): 6.391

Gingival Index (GI):

The Gingival Index (Löe and Silness, 1963) was created for the assessment of the gingivalcondition and records qualitative changes in the gingiva. It scores the marginal andinterproximal tissues separately on the basis of 0 to 3 . The criteria are: ${ }^{(62)}$

\begin{tabular}{|c|c|}
\hline Scores & Criteria \\
\hline 0 & Normal gingival \\
\hline 1 & $\begin{array}{c}\text { Mild inflammation - slight change in color and slight } \\
\text { edema but no bleeding on probing }\end{array}$ \\
\hline 2 & $\begin{array}{c}\text { Moderate inflammation - redness, edema and glazing, } \\
\text { bleeding on probing; }\end{array}$ \\
\hline 3 & $\begin{array}{c}\text { Severe inflammation - marked redness and edema, } \\
\text { ulceration with tendency to spontaneous bleeding. }\end{array}$ \\
\hline
\end{tabular}

\section{Instrument :}

-Kidney dish

-Mask

-Towels

$\begin{array}{ll}\text {-Periodontal probe } & \text {-Gloves } \\ \text {-Cotton } & \text {-Alcohol } \\ \text {-Dental mirror } & \text {-Tweezers }\end{array}$

\section{Results and Discussion}

A total of 40 patients, comprising $20(50 \%)$ control and 20 $(50 \%)$ chewing gum, consented to take part in the study. The control were assigned to group (A), and the chewing gum patients were assigned to group (B). We used SPSS statistics v.15 for statistical analysis and Microsoft Excel 2007 for figures.

For descriptive statistics we used :

1-mean.

2-standard deviation (SD).

3-standard error (SE).

For invertialstatitistics we used :

1 -t-test.

2-probability p-value.

Table 2: description of PI and GI of chewing gum subjects :

\begin{tabular}{|c|c|c|}
\hline Chewing & PI & GI \\
\hline $1^{\text {st }}$ week & $1.24 \pm 0.76$ & $1.44 \pm 0.35$ \\
\hline $2^{\text {st }}$ week & $0.83 \pm 0.76$ & $0.66 \pm 0.25$ \\
\hline $3^{\text {st }}$ week & $0.69 \pm 0.67$ & $0.65 \pm 0.27$ \\
\hline
\end{tabular}

Table 3: description of PI and GI of control subjects :

\begin{tabular}{|c|c|c|}
\hline Control & PI & GI \\
\hline $1^{\text {st }}$ week & $1.57 \pm 1.06$ & $1.44 \pm 0.35$ \\
\hline $2^{\text {st }}$ week & $0.77 \pm 0.57$ & $0.66 \pm 0.25$ \\
\hline $3^{\text {st }}$ week & $0.57 \pm 0.46$ & $0.65 \pm 0.27$ \\
\hline
\end{tabular}

\section{Plaque Index and gingival index}

The following tables and figures summarizes the descriptive statistics of group A and B regarding plaque index (PI) and gingival index (GI).

Table 4: Descriptive statistics of group A

\begin{tabular}{|c|c|c|}
\hline Chewing & PI & GI \\
\hline Mean & 0.9800 & 1.0350 \\
\hline SD & 0.3195 & 0.3606 \\
\hline SEM & 0.1845 & 0.2550 \\
\hline
\end{tabular}

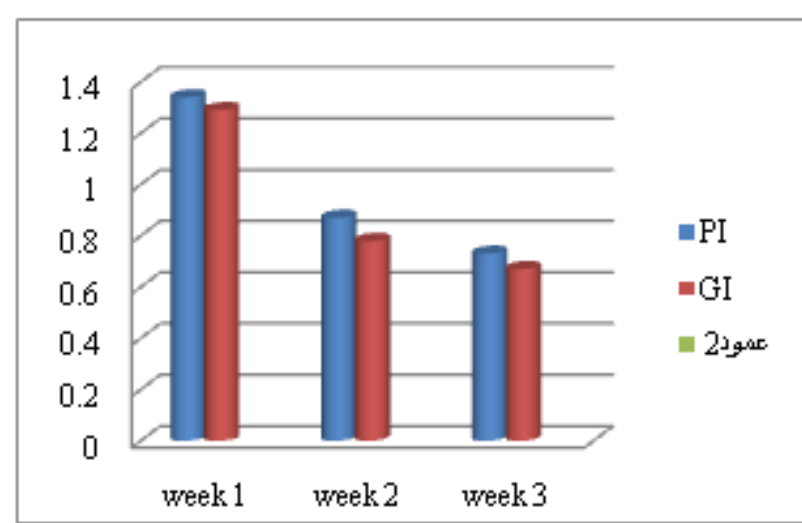

Figure 1: Descriptive statistics of group A

As we see in the figure (1) there are high differences between PI and GI of chewing gum patient between the first andsecond week, but there is a very slight differences between the second and third week this may be due to the loss of patients motivation which they gained in the first week so we must do a continuous patient motivation in every visit of our treatment.

Now if we see the descriptive statistics of patients of group B (see figure 2) we also see a results similar to group A also there are high differences between the first and second week and slight differences between the second and third week and we think it is due to the same reasons of group A.

Table 5: Descriptive statistics of group B

\begin{tabular}{|c|c|c|}
\hline Control & PI & GI \\
\hline Mean & 1.0400 & 1.0033 \\
\hline SD & 0.2546 & 0.3256 \\
\hline SEM & 0.1800 & 0.1880 \\
\hline
\end{tabular}

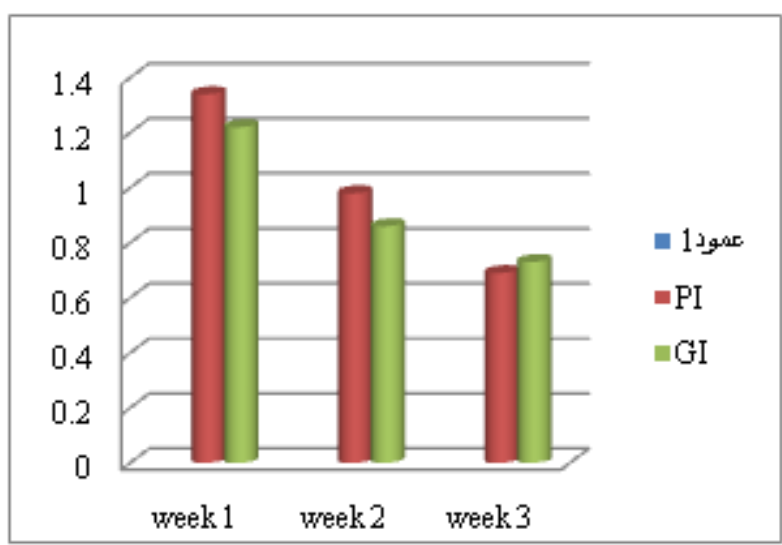

Figure 2: Descriptive statistics of group B

If we compare between the results of group (A) and (B) we will found the following results (see figure 3 ). 


\section{International Journal of Science and Research (IJSR) \\ ISSN (Online): 2319-7064}

Index Copernicus Value (2015): 78.96 | Impact Factor (2015): 6.391

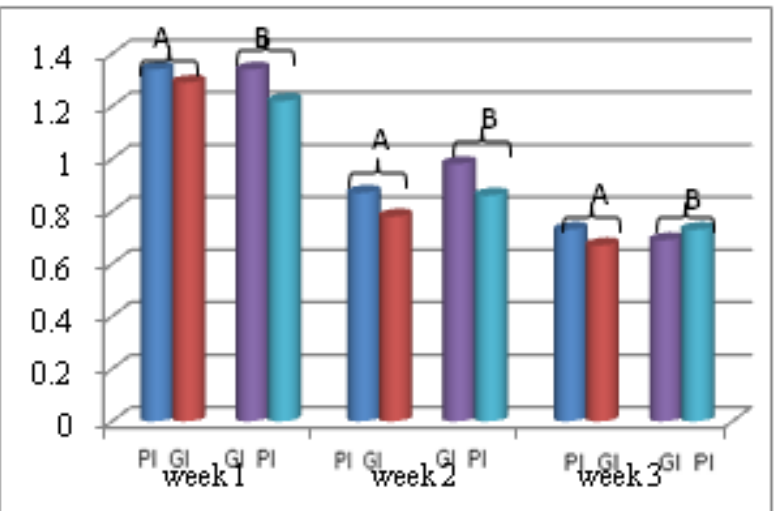

Figure 3: A comparison between the descriptive of group A and $\mathrm{B}$

As we can see, the chewing gum patient show slightly higher decrease in plaque index and gingival index between the first and second week than the control patient while there is no mark differences in decreasing of the plaque index and gingival index of the second and third week. These differences were statistically not significant as shown in table(6).

Table 6: Show (t-test) for (PI) and (GI) between group A

\begin{tabular}{|c|c|c|}
\hline & t-test & p-value \\
\hline PI & 1.1818 & 0.4471 \\
\hline GI & 0.1027 & 0.9247 \\
\hline
\end{tabular}

$* p<0.05$ significant

The result of our study didn't support the study of (Addy M, Perriam G. Sterry A. Effects of sugared and sugar free chewing gum on the accumulation of plaque and debris on the teeth. J Clin Periodontal. 1982; 9:326-54.) and ( Hoerman KC, Gasior EJ, Zibell SE, Record D,Flowerdew G. Effect of chewing gum on plaque accumulation. J Clin Dent. $1990 ; 2: 17-21$.) which state that (chewing gum, irrespective of sweetener caused significantly less plaque accumulation than not chewing gum $\}$.

This result which we reached may be due to either inadequate number of subjects, or uncooperative subjects, or it is may be due to insufficient number of chewing gum that have been used per day.

We suggest increase the number of subjects in the next studies, increase the number of visits that we examine the subject during it and increase the number of times of using the chewing gum daily all these can give us more accurate results.

In conclusion, as health care providers, we should include in our dental education programmes the role of chewing gum as an adjunct to individual self-care such as routine daily brushing, flossing and regular dental check. With the various community-based preventive measures underway, it is likely that chewing sugar-free gum can play an important role in the improvement of oral health status of the country.

\section{References}

[1] Mathews M, Jia HP, Guthmiller JM, Losh G, Graham S, JohnsonGK, Tack BF, McCray PB Jr. Production of beta-defensin antimicrobialpeptides by the oral mucosa and salivary glands. Infect Immun1999; 67: 2740-2745.

[2] Krisanaprakornkit S, Kimball JR, Weinberg A, Darveau RP, Bainbridge BW, Dale BA. Inducible expression of human beta-defensin 2 by Fusobacteriumnucleatum in oral epithelial cells: multiple signalingpathways and role of commensal bacteria in innate immunityand the epithelial barrier. Infect Immun 2000; 68: 2907-2915.

[3] Lu Q, Jin L, Darveau RP, Samaranayake LP. Expression of humanbeta-defensins-1 and -2 peptides in unresolved chronic periodontitis.J Periodontal Res 2004; 39: 221-227.

[4] Bissell J, Joly S, Johnson GK, Organ CC, Dawson D, McCrayPBJr, Guthmiller, JM. Expression of betadefensins in gingivalhealth and in periodontal disease. $\mathbf{J}$ Oral Pathol Med 2004; 33: 278-285.

[5] Dunsche A, Acil Y, Dommisch H, Siebert R, Schroder $\mathrm{JM}$, JepsenS. The novel human beta-defensin-3 is widely expressed in oral tissues.Eur J Oral Sci 2002; 110: 121-124.

[6] Ponnuswamy M., Menaga V.,Rajappan R., "Oral health: Role of chewing gum”, Brunei Int Med J. 2011; 7 (3): 130-138.

[7] Addy M, Perriam G. Sterry A. Effects of sugaredand sugar free chewing gum on the accumulation ofplaque and debris on the teeth. J Clin Periodontal.1982; 9:32654.

[8] Hoerman KC, Gasior EJ, Zibell SE, Record D,Flowerdew G. Effect of chewing gum on plaque accumulation.J Clin Dent. 1990; 2:17-21.

[9] Kleber CJ, Putt MS, Milleman JL, Davidson KR,Proskin HM. An evaluation of sodium bicarbonatechewing gum in reducing dental plaque and gingivitisin conjunction with regular tooth brushing. CompendContinEduc Dent. 2001; 22:4-12.

[10] Soparkar P, Newman MB. Effects of a bakingsoda gum on extrinsic dental stain. Results of alongitudinal 4 week assessment. CompendContEduc Dent. 2001; 22:25-28.

[11] Smith A, Moran J, Danglier L, Leight RS, AddyM. The efficacy of an anti gingivitis chewing gum. JClinPeriodontol. 1996; 23:19-23.

[12] Simons D, Brailsford S, Kidd EA, Beighton D.The effect of chlorhexidine acetate/xylitol chewinggum on the plaque and gingival indices of elderlyoccuppants in residential homes. J ClinPeriodontol.2001: 28;1010-15.

[13] Kimbrough C, Chun M, dela Roca G, Lau BH.Pycnogenol chewing gum minimizes gingival bleedingand plaque formation. Phytomedicine 2002;9:410-3.

[14] Nagata $H$, Inagaki $Y$, Tanaka $M$ et al. Effect ofeucalyptus extracts chewing gum on periodontalhealth: a double-masked randomized trial. JPeriodontol 2008. 2010; 79:1378-85.

[15]Dalal K. Chewing gum Trick or treat? SaudiDent J. 1999; 11:27-31

[16] Fascinating facts about the invention of chewing gum by Thomas Adams in 1845. The Great Idea Finder Web site.

Available at: http://www.ideafinder.com/history/inventions/story0 56.htm. Accessed May 22, 2004.

[17] A Symposium on the Endogenous Benefits of Saliva in Oral Health. March 21, 1989. LSU School of Dentistry, 


\section{International Journal of Science and Research (IJSR) \\ ISSN (Online): 2319-7064}

Index Copernicus Value (2015): 78.96 | Impact Factor (2015): 6.391

New Orleans, LA. Compend Suppl. 1989;(13):S448S488.

[18] Dawes C. Physiological factors affecting salivary flow rate, oral sugar clearance, and the sensationof dry mouth in man. J Dent Res 1987; 66:648-653.

[19] Richardson CT, Feldman M. Salivary response to food in humans and its effect on gastric acidsecretion. Am J Physiol 1986; 250(1 Pt 1):G85-G91.

[20] Watanabe S, Dawes C. A comparison of the effects of tasting and chewing foods on the flow rateof whole saliva in man. Arch Oral Biol 1988; 33:761-764.

[21] Dawes C. Circadian rhythms in human salivary flow rate and composition. J Physiol 1972;220:529-545.

[22] Ferguson DB, Botchway CA. Circadian variations in flow rate and composition of humanstimulated submandibular saliva. Arch Oral Biol 1979; 24:433437.

[23] Christensen CM. Food texture perception. Adv Food Res 1984; 29:159-199. 